\title{
Condom Use among HIV infected clients seeking care at Rimuka Integrated HIV and Tuberculosis Site, Kadoma, Zimbabwe 2015.
}

\author{
Article by Daniel Chirundu \\ MPH, Texila American University, Zimbabwe \\ Email: dchirundu@texilaconnect.com
}

\begin{abstract}
Condom Use among HIV infected clients seeking care at Rimuka Integrated HIV and Tuberculosis Site, Kadoma, Zimbabwe 2015. Daniel Chirundu, Brian Shawarira, Rumbidzai Kazingizi, Pamela Nyaradzai Magande

Introduction. Inconsistent use of condoms among HIV the infected during vaginal sex is a cause of concern. Its can lead to STI, unwanted pregnancies and infection with resistant strains of HIV. A study done in Kadoma revealed that among the respondents $35 \%$ had not used condoms during their last sexual encounter. It is against this background that we investigated factors associated with condom use among HIV clients seeking care .

Methodology. We used an analytical cross sectional study design. The study population were HIV infected clients seeking care at Rimuka Clinic. A sample size of 150 respondents were conveniently recruited. Data were captured using a pretested administered questionnaire. Data were analysed using EpiInfo 7 statistical software. Written informed consent was obtained from respondents.

Results. We interviewed 150 respondents. The prevalence of consistent condom use in the 3 months prior to the study was 52\% among females and 37\% among males. Factors positively associated with condom use were partners positive feelings on condom $O R=7$ $p<0.05$. Factors negatively associated with condom use were being gainfully employed $O R=$ $0.4 p<0.05$; perception that condoms reduce sexual pleasure $O R=0.2 p<0.05$; thinking that there is no need for a condom in a long term union, $O R=0.29 p=0.02$, no need for condom if $H I V$ positive $O R=0.11 p=0.01$; perceptions that condoms are for use by prostitutes $O R=0.23$ $p=0.04$.

Conclusion: Correct consistent condom use should be encouraged among the HIV infected.
\end{abstract}

Keywords: Condom Use, HIV infected, Kadoma Zimbabwe

\section{Introduction}

A study carried out by in 2014 among HIV clients seeking services at a primary health care clinic in Kadoma (Zimbabwe), revealed that $35 \%$ of the respondents had not used a condom during the last vaginal sexual encounter ${ }^{1}$. Non condoms use among the HIV infected is a cause of concern. This could lead to infection of uninfected partners, HIV reinjection, unwanted pregnancies, and/or sexually transmitted infections (STI $)^{2,3,4}$.

It is against this background that we investigated factors associated with condom use among HIV Infected seeking acre at Rimuka Clinic.

\section{Methodology}

\section{Study Design}

This was an analytical cross section study. The study participants were registered clients seeking HIV care at Rimuka ITHC in Kadoma.

\section{Sampling Procedure}

Using a sampling frame of HIV infected clients in the register at Rimuka IHTC, convenient sampling was used and clients seeking HIV care were selected at Rimuka ITHC. 
South American Journal of Public Health

Special Edition May 2016

\section{Sample Size}

Using Dobson formula and assuming condom use $78.9 \%$ on the last sexual encounter powered on a study by Zewdneh Shewamene et. $a l^{5}$. The calculated sample size was 150 .

\section{Data Collection and Analysis}

Structured pretested questionnaires were used to collect data. The questionnaires combined level of knowledge, barriers and attitudes to condom use. The questions were on sociodemographic data of respondents, knowledge of HIV/AIDS infection, knowledge of condom, accessibility and utilization of condom.

Epi. Info ${ }^{7}$ (CDC), 2014 TM statistical analysis package and Microsoft excel 2013 was used to analyse the data. The software was used to generate frequencies, means and odds ratios and chi square. A forward logistic regression model was used to identify independent factors.

\section{Definition of Variables}

Outcome Variable. The outcome variable in this study was coded "consistent condom use". The variable was created in analysis by assigning as consistent condom users those who reported using condoms "every time" during vaginal intercourse in the three months prior to the study. Those whose response was "almost all the time (90\% of the time)", or, "sometimes" or "never" used a condom were classified as inconsistent condom user. Condom use was measured as a dichotomous variable (single event measure) as well as a frequency measure on a scale with a recall period of three months on vaginal sex.

Independent Factors. All other variables were categorised into a dichotomous "yes" or "not". Any respondent who reported use of alcohol "every time", "almost every time" or "some time" before or during sex was deemed for the purpose of analysis to be "alcohol or substance users" during sex. On condom future use, only those who indicated they are "very sure" in future they will use condoms were considered likely future users.

\section{Monogamous Relationship}

Those who responded that they were "sexually active with one partner" and those who were "certain neither of them had sex with anyone else" where classified for analysis as being in "monogamous relationships" three months prior to the study. On recoding attitudes and perceptions as dichotomous "Strongly agree" and "agree" were re-coded as affirmation of the statement posed.

\section{Ethical Considerations}

Permission to proceed was obtained from the association for People Living with HIV and Aids, and Kadoma City Council. Written informed consent was obtained from all participants.

\section{Results}

\section{Study Respondents}

A total of 150 respondents were recruited into the study. Ninety six (64\%) were females and fifty four (36\%) were males. The age and sex distribution of the respondents is presented in Figure 1. The median age of the males was 42 years $(\mathrm{Q} 1=33.5 \mathrm{Q} 3=50)$ with a range of 60 years. For females the median age was 36.5 years $(\mathrm{Q} 1=30$ : Q3=42) and the range was 38 years. The mean age for females was 36.58 years and that for males was 42.85 years. There was a statistically significant different in the mean ages using the student t-test $(p=0.0006)$.

\section{Marital Status}

The marital status of the respondents by sex is shown in figure 2 . Among the respondents, $104(69.30 \%)$ reported that they were married. Thirteen (8.67\%) where divorced whilst 8 (5.30\%) where on separated. 


\section{Respondents’ Education}

The educational attainment of the respondents is shown in figure 3. We found out that the majority of the respondents had attained a secondary school level of education. A higher proportion of females had attained a primary school level of education than males.

\section{Employment and Income}

Among the respondents 26\% employed, 33\% unemployed and 41\% self employed. Among the employed respondents 14 (25.5\%) were males compared to 9 (9.38\%) females. Eighteen (33\%) of the male respondents were not in employment compared to 51 (53.13) females. The median income was US $\$ 100$ (Q1=US\$100; Q3=US\$200). The income range was US\$1400.00. The mean income for males was \$228.73 and that for females was \$144.61. There was a statistically significant difference in the mean incomes using the student t-test for independent variable $\mathrm{t}=2.56(p=0.00114)$.

\section{Respondents Religion}

Of the 96 female respondents 91 (95\%) reportedly went to church whilst 44 (81\%) of the males respondents reportedly went to church. Forty percent of the respondents attended a Pentecostal church. This was followed by Apostolic sects. Other churches mentioned include Catholic and Johane Masowe among others.

\section{Perceptions of Condom Use among Congregants}

Among the respondents who were Pentecostal, 32\% thought condoms were allowed whilst $38 \%$ thought they were not allowed $(\mathrm{p}=0.74)$. The majority of the Apostolic sects $21.05 \%$ indicated condoms are allowed whilst $17.90 \%$ indicated they were not $(p=0.85)$. Among the respondents $12.63 \%$ of the reported Catholics indicated that condoms are allowed and $10 \%$ indicated they are not $(p=0.91)$.

\section{Frequency of Sex}

The frequency of vaginal sexual intercourse among the respondents is presented in figure 4. The majority of males (63\%) and females (49\%) reported they have sex several times a week. A greater proportion of females $17 \%$ indicated they had sex once in three months compared to $4 \%$ among males.

\section{Use of Alcohol/Substances before Sex by Respondent}

On being asked about alcohol or other substance use before or during sex 121 (81\%) of the respondents indicated that they have never used alcohol. However, 29 (19\%) indicated they used alcohol or other substances in varying degrees. On being asked if their sexual partners used also or other substances before or during sex, 4 (7.41\%) of the males indicated yes and $40(41.67 \%)$ of the females indicated yes. The differences in proportions was not statistically significant $(\mathrm{p}=0.25)$

\section{Sexual Behaviours Three Months Prior the study}

Sexual behaviours three months prior to the study are shown in figure 5. Among the respondents, 103 (69\%) indicated they were sexually active with one partner, 22, (15\%) indicated they were sexually active with more than one partner. Seventeen(11\%) were sexual active with one partner; however, they felt the partner was having a sexual relationship with someone else.

\section{Prevalence of Consistent Condom use}

The respondents that were classified as consistent condom user are shown in Table 1 . There were 50 (52\%), female consistent users and 20 (37\%) male consistent users. There was no significant difference in proportions of consistent and inconsistent users across sexes $(\mathrm{p}=0.07)$. 
South American Journal of Public Health

Special Edition May 2016

\section{Consistent Condom Use and Marital Status}

The proportion of consistent and non-consistent user is shown in figure 6. Sixty two per cent of the married respondents were inconsistent use of condoms three months prior to the study whilst $44 \%$ were not consistent users. The difference in proportions among the married consistent and non-consistent condom user was not statistically significant $(\mathrm{p}=0.75)$

\section{Prevalence of Consistent Use by Employment}

The prevalence of consistent condom use by employment status is presented in figure 7 . Prevalence of consistent condom use was lowest among the employed.

\section{Condom Use on Last Vaginal Sex Encounter}

Among the male respondents 42(77.8\%) indicated they had used a condom on last Vaginal Sex Encounter compared to 72 (75\%) of the female respondent. The difference in proportions was not statistically significant ( $\mathrm{p}=0.7$ ).

\section{Frequency of Condom Use with Main Partner}

Respondents were asked the frequency of condom use 3 months prior to the study with their main partner. The results are shown in figure 8. A higher proportion of female respondents (19.7\%) compared to $12.5 \%$ of the males (16.7\%) indicated they never used a condom with the main sex partner. Among those who indicated they used "every time" $52 \%$ were males compared to $37 \%$ females. The difference in these proportions was not statistically significant $(\mathrm{p}=0.25)$.

\section{Intention to Use Condom in Future by Sex}

The intention to use condom in future as presented by the respondents is shown in figure 9 . More than $70 \%$ of the respondents were very sure they would use a condom in future sex encounters. However, there were $3 \%$ of the female respondents who were "very sure" they will not use condoms.

\section{Risky Sexual Behaviour}

On being asked if they were in a monogamous relationship in the previous three months, $39(26 \%)$ of the respondents indicated they were not. Of these $(n=39), 14(25.93 \%)$ were males and 25 (26.04\%) were females. The difference in the proportions was not statistically significant ( $\mathrm{p}=0.99)$. However, on being asked if they had casual sex in the three months prior to the study 20 respondents (13.33\%) indicated yes whilst 130 (86.67\%) only had sex with the main sex partner. Among those who had casual sex 12 (22.22\%) were males $(n=54)$ and 8 $(8.33 \%)$ were females $(n=96)$. The differences in the proportions was statistically significant $(\mathrm{p}=0.0164)$.

\section{History of Sexually Transmitted Infection Treatment}

Among the respondent 35 (23.33\%) indicated they had been told by a medical worker at one time that they had a sexual transmitted disease.

\section{Bivariate Analysis}

The associations between demographic factors and consistent condom use in the previous three months prior to the study are shown in table 2. Respondents who were staying with a partner were 1.8 times more likely to use condoms consistently. Those who were gainfully employed, had attained a secondary level of education and were below 40 years of age were not likely to report consistent condom use in the three months prior to the study.

\section{Sexual Behavior and Consistent Condom Use}

Table 3 is a presentation of the correlation between sexual behavior and consistent condom use. Being sexually active with one main partner in the three months prior to the study, use of 
drugs and alcohol before or during sex, having sex several times a week were positively associated with consistent condom use. Reporting having a casual sex partner, and thinking that partner had sex with someone with no condom were negatively associated with consistent condom use. However, all these associations were not statistically significant( $p>0.05)$.

\section{Association between Reasons for Condom Use and Consistent Condom Use}

The associations between reasons for condom use and consistent condom use are presented in table 4. There were positive associations between condom use and the perception that condoms can prevent pregnancy and/or transmission of disease. Those who reported using a condom as a way of preventing "spreading of disease" were 5.3 times more likely to have consistently used condoms three months prior to the study. Those who reported receiving condom education were 1.9 times more likely to report consistent condom use $(p=0.06)$. Being diagnosed with an STI was negatively associated with consistent condom use $\mathrm{OR}=0.6$, $\mathrm{p}=0.19$

The association between effect of significant others and condom use is shown in table 5 . Those who perceived their partners to have positive attitudes towards condoms, and those whose churches purportedly encouraged condom use were more likely to report consistent use of condoms.

\section{Accessibility of Condoms}

The association between accessing condoms and condom use is presented in table 6 . There were positive associations between thinking that condoms are affordable, knowing where to get condoms for free and thinking that condoms were easily accessible. However the associations were not statistically significant.

\section{Condom Perception and Consistent Condom Use}

Bivariate analysis of perception on condoms and consistent condom use are presented in table 7. There was a positive association between perceiving that condoms prevent HIV reinfection and consistent condom use. However, there was a negative association between thinking condoms reduce sexual pleasure, that there is no place for condoms in long term relations finding it embarrassing to get condoms and consistent condom use.

\section{Multiple Logistic Regressions}

In a multiple logistic regression model, all the factors that were significant in bivariate analysis remained statistically significant at $95 \%$ confidence level. The independent factors are shown in table 8.

\section{Discussion/Conclusion}

This was an analytical cross sectional study whose broad objective was to determine factors associated with condom use among HIV infected clients. Fifty per cent of the respondents were between the ages of 31.5 years and 45.5 years. This is the sexually active group, and if married, they would aspire to have children. The desire to have children is negatively associated with condom use ${ }^{5}$. Sexually activity was high among both male and female respondents with $54 \%$ of the respondents having sex several times a week. This makes condom use important as there is risk of unwanted pregnancy, STI or reinfection with every sexual encounter if condoms are not used correctly and consistently.

We found a higher proportion of female respondents using a condom "every time" in three months prior to the study, in unions compared to men. This is an indication that there are still some people who hold the correct view that condoms have a place in marriage. Whist some respondents indicated use of condoms $90 \%$ of the time or sometimes this places them at risk of reinfection, unwanted pregnancies and STI.

In this study condom use was not associated with education and this was consistent with the study carried out by Delgado et. al. ${ }^{6}$. However, in other studies higher education was positively reported to be associated with consistent condom use ${ }^{7,8,9}$. 
Being gainfully employed was negatively associated with consistent condom use. This could be because being employed may translate into higher purchasing power for sex as well as higher bargaining power for non-protected sex. Same was reported by Elmes et. al. in a study in Zimbabwe in where clients paid on average $42.9 \%$ more for unprotected sex ${ }^{10}$.

In bivariate analysis we found that having a church that encourages condom use was a predictor although it was not statistically significant $(p=0.07)$. The partners, and the church leaders can be viewed as significant others who can positive influence condom use.

Those in a union were 1.8 times more likely use condoms consistently. Our findings are consistent with the finding of Akinyeni et. al. (2010), in a study in Nigeria who reported that respondents in a union were likely to use condoms consistently ${ }^{11}$. Gregson et. al. however, in a study in Zimbabwe reported increased condom use with casual partners, but not with regular partners ${ }^{12}$.

Contrary to reports by Heidi Reynolds we found that having a partner with a positive attitude towards condoms was a predictor of condom use $(p<0.05) 13$. However, this should be interpreted with caution as reported by Cordero-Coma et. al. that having been informed about HIV prevention induced respondents to over-report condom use within marriage in a survey $^{14}$. This maybe one of the weakness of this study.

We found out that alcohol use was positively associated with consistent condom use. This is consistent with what was reported by Denue et. al. in a study done among HIV infected people in Nigeria ${ }^{14}$. Elsewhere, Rizwan et. al. reported that men who consumed alcohol were three times more likely not to use a condom at their last non-spousal sexual encounter. However, the study was done in the general population.

In this study we found associations between use of condoms to prevent pregnancy, to prevent transmission or acquisition of diseases. In a study carried out in Zimbabwe by Callegari et. al. (2008), perception of male condoms as very effective in pregnancy prevention was associated with consistent condom use ${ }^{15}$. This provides an opportunity for introduction of condoms in marriage.

We found a negative association between the perception that condoms reduce sexual pleasure and consistent condom use. Randolph et. al. (2007) reported that both women and men rated unprotected vaginal intercourse as more pleasurable than protected vaginal intercourse $^{16}$. Wrong perceptions can influence condom use. There is need for a structured way to change the perceptions on condoms and pleasure at community level if further inroads are to be made in condom use promotion.

We also found a negative association between a history of STI and consistent condom use. This is similar to what was reported in a study carried out in Ethiopia by Yalew et. $a l^{5}$. Rizwan et. al. (2004) in a study carried out in India also reported that those with a history of STI were 1.95 times more not to use a condom ${ }^{17}$.

Based on this research our conclusions are that the prevalence of consistent condom use among the respondents was $46 \%$. There was no significant difference in the proportions of males and females who consistently used condoms. Females had better health seeking behaviours than males as attested by a significantly higher proportion of women seeking HIV services than males. There were respondents who were in one relationship but have evidence of their partners being in other relationships. Under the circumstances this should be a cue to action to consistently use condoms. A significant proportion of the married respondents had to seek sexual pleasure outside the matrimonial union and this predisposes to reinfection if condoms are not used. The respondents in the study had a relatively healthy sex life with 54\% reporting having sex several times a week. This may be comparable to the general population.

Staying with a partner and being sexually active with one partner was positively associated with consistent condom use. Having sex several times a week was also a predicator of consistently condom use. Education on condom use was also a predictor of consistently condom use. Motivation behind using a condom like prevention of pregnancies, preventing acquisition of diseases and prevention transmitting diseases are predictors of consistent condom use. Partners' positive feeling on condoms was a predictor of consistent condom use. 
Being employed, attaining a secondary education, being male and age below 40 years were predictors of non consistent condom use. Those who perceived that their partners were having sex with another person without using a condom were also not consistent condom users in their monogamous relationships. Negative perceptions on the pleasure reducing effect of condoms was a barrier to consistent condom use. A previous history of a sexually transmitted disease was also found to be a barrier to condom use.

The majority of respondents had positive attitude towards condom use in as far as perceiving that procuring condoms is not embarrassing, in that people in long term relationships need to use condoms, condoms are not only for use by prostitutes, that there is need for condoms even among the HIV infected and that condoms prevent reinfection. However, there were mixed perceptions among the respondents whether condoms reduce sexual pleasure or not.

In light of the results our recommendations are that Condom use among married HIV infected couples should be promoted just like in the general population. Condom use education should be strengthened among those seeking STI treatment including those already infected by HIV.

Males are to be encouraged to seek medical care for HIV infection. Combined HIV education sessions programs to be offered to couples and to cover aspects of proper condom use, and, dangers of multiple partners. HIV infected persons to be encouraged to use condoms in when they have sexual intercourse with non- main partners. Those who suspect partners of extramarital affairs to be given skills to negotiate and use condoms.

Health authorities need to work on the perceptions that condoms reduce sexual pleasure and targeting the opportunity cost of reinfection, unwanted pregnancy could be cue to action. Condoms to be placed and distributed from areas were people will not feel embarrassed procuring them. Churches and significant others to play a clear role in promoting condom use among members and friends. Churches should discuss sexuality openly and make clear its doctrine on condoms.

\section{References}

[1.] Ballah Akawu Denue et. al. (2014). Evaluation of Condom Use and Associated Factors among Adult HIV Clients in Maiduguri, North Eastern Nigeria: A Comparative Cross Sectional Study. World Journal of AIDS, 2014, 4, 169-177

[2.] Callegari L et. al. (2008). Consistent condom use in married Zimbabwean women after a condom intervention. Sex Transm Dis. 2008 Jun;35(6):624-30. doi: 10.1097/OLQ.0b013e31816b3208.

[3.] Daniel Chirundu (2014). HRQL Among HIV Infected at Rimuka- Capstone 2014 In press

[4.] Delgado Hurtado et. al. (2011). Knowledge of HIV transmission and condom use among HIVpositive heterosexual men and women in Guatemala. Journal of the International AIDS Society 2011, 14:58

[5.] Dessie Y, et. al. (2011). Risky sexual practices and related factors among ART attendees in Addis Ababa public hospitals, Ethiopia: a cross-sectional study. BMC Public Health. 2011;11:422.

[6.] Elmes J et. al. (2014). The price of sex: condom use and the determinants of the price of sex among female sex workers in eastern Zimbabwe. J Infect Dis. 2014 Dec 1;210 Suppl 2:S569-78. doi: 10.1093/infdis/jiu493

[7.] Gregson S et. al. (2006). HIV decline associated with behavior change in eastern Zimbabwe. Science. 2006 Feb 3;311(5761):664-6

[8.] Heidi W. Reynolds (2012). The Measurement of Condom Use in Four Countries in East and Southern Africa. AIDS Behav. 2012 May; 16(4): 1044-1053. doi: 10.1007/s10461-012-0146-9

[9.] Joshua O. Akinyemi, et. al. (2010). Condom use among antiretroviral therapy patients in Ibadan, Nigeria. J Infect Dev Ctries 2010; 4(8):495-502.

[10.] Julia Cordero Coma et. al. (2014). HIV prevention and marriage: Peer group effects on condom use acceptability in rural Kenya. SOCIAL Science \& Medicine 116:169- 177 September 2014

[11.] Kefyalew Addis Alene et. al. (2014). Consistent condom use among sexually active HIV-positive women in Amhara region, Ethiopia. Open Access Journal of Contraception 2014:5 85-90 
South American Journal of Public Health

Special Edition May 2016

[12.] Mary E. Randolph et. al. (2007). Sexual Pleasure and Condom Use. Arch Sex Behav. 2007 Dec; 36(6): 844-848. 17. S A Rizwan et. al. (2014). Correlates of Intention to Use Condom among Male Migrant Factory Workers in Northern India. J Clin Diagn Res. 2014 Aug; 8(8): JC05- JC08

[13.] Pedraza MA et. al.(1999). Heterosexual transmission of HIV-1 is associated with high plasma viral load levels and a positive viral isolation in the infected partner. J Acquir Immune Defic Syndr. 1999 Jun 1;21(2):120-5

[14.] Stolte IG et.al. (2001). Increase in sexually transmitted infections among homosexual men in Amsterdam in relation to HAART. Sex Transm Infect 77: $184-186$.

[15.] Yalew et. al. (2012). Patterns of condom use and associated factors among adult HIV positive clients in North Western Ethiopia: a comparative cross sectional study. BMC Public Health 2012, 12:308

[16.] Zewdneh Shewamene et. al. (2015). Consistent condom use in HIV/AIDS patients receiving Antiretroviral therapy in northwestern Ethiopia: Implication to reduce transmission and multiple infections. HIV/AIDS - Research and Palliative Care 2015:7 119-124)

\section{List of Tables}

Table 1: Consistent/Inconsistent Condom Use by Sex

\begin{tabular}{lll}
\hline Condom User & Females & Males \\
\hline Consistent User $(n=70)$ & $50(52.08 \%)$ & $20(37.04 \%)$ \\
\hline Non Consistent User $(n=80)$ & $46(47.92 \%)$ & $34(62.96 \%)$ \\
\hline Total $(n=150)$ & $96(100 \%)$ & $54(100 \%)$ \\
\hline
\end{tabular}

Table 2: Bivariate Analysis Demographic factors and Condom Use

\begin{tabular}{|c|c|c|c|c|c|c|}
\hline \multirow[t]{2}{*}{ Demographic Factors } & & \multicolumn{2}{|c|}{$\begin{array}{l}\text { Consistent } \\
\text { Condom Use }\end{array}$} & \multirow[t]{2}{*}{ OR } & \multirow[t]{2}{*}{ 95\% CI } & \multirow[t]{2}{*}{ p-value } \\
\hline & & Yes & No & & & \\
\hline \multirow[t]{2}{*}{ Sex } & Male & 20 & 34 & 0.5 & $0.2-1.07$ & 0.07 \\
\hline & Female & 50 & & & & \\
\hline \multirow[t]{2}{*}{ Age Below 40 years } & Yes & 38 & 47 & 0.8 & $0.43-1.5$ & 0.58 \\
\hline & No & 32 & 33 & & & \\
\hline \multirow[t]{2}{*}{ Staying with Partner } & Yes & 54 & 52 & 1.8 & $0.8-3.7$ & 0.1 \\
\hline & No & 16 & 28 & & & \\
\hline \multirow[t]{2}{*}{ Attained Secondary Education } & Yes & 50 & 62 & 0.72 & $0.34-2.5$ & 0.39 \\
\hline & No & 20 & 18 & & & \\
\hline \multirow[t]{2}{*}{ Gainfully Employed } & Yes & 30 & 51 & 0.4 & $0.22-0.8$ & 0.01 \\
\hline & No & 40 & 29 & & & \\
\hline
\end{tabular}

Table 3: Bivariate Analysis- Sexual Behavior and Consistent Condom Use

\begin{tabular}{|c|c|c|c|c|c|c|}
\hline \multirow[t]{2}{*}{ Sexual Factors } & & \multicolumn{2}{|c|}{$\begin{array}{l}\text { Consistent } \\
\text { Condom Use }\end{array}$} & \multirow[t]{2}{*}{ OR } & \multirow[t]{2}{*}{$95 \%$ CI } & \multirow[t]{2}{*}{ p-value } \\
\hline & & Yes & No & & & \\
\hline \multirow[t]{2}{*}{ Use of drugs/alcohol before/during sex } & Yes & 16 & 13 & 1.5 & $0.67-3.4$ & 0.3 \\
\hline & No & 54 & 67 & & & \\
\hline \multirow[t]{2}{*}{ Have sex several times a week } & Yes & 39 & 42 & 1.13 & $0.59-2.1$ & \\
\hline & No & 31 & 38 & & & \\
\hline \multirow[t]{2}{*}{ Sexual Active with 1 partner } & Yes & 49 & 54 & 1.12 & $0.56-2.2$ & 0.74 \\
\hline & No & 21 & 26 & & & \\
\hline \multirow[t]{2}{*}{ Had sex with non-main sexual partner } & Yes & 7 & 13 & 0.5 & $0.21-1.52$ & 0.26 \\
\hline & No & 63 & 67 & & & \\
\hline \multirow[t]{2}{*}{ Partner use alcohol or drugs during sex } & Yes & 23 & 21 & 1.3 & $0.67-2.78$ & 0.37 \\
\hline & No & 47 & 59 & & & \\
\hline Partner had sex with someone with no & Yes & 17 & 20 & 0.96 & $0.45-2.07$ & 0.91 \\
\hline
\end{tabular}


No $53 \quad 60$

Table 4. Associations between Reasons for Condom Use and Consistent Condom Use

\begin{tabular}{lllllll}
\hline Reasons for Use of Condoms & \multicolumn{7}{c}{$\begin{array}{l}\text { Consistent } \\
\text { Condom Use }\end{array}$} & OR & 95\% CI & p-value \\
& \multicolumn{9}{c}{ Yes } & No & & & \\
\hline Education on Condom Use & Yes & 66 & 68 & 2.9 & $0.89-9.4$ & 0.06 \\
& No & 4 & 12 & & & \\
Pregnancy Prevention & Yes & 51 & 44 & 1.7 & $0.82-3.4$ & 0.14 \\
& No & 19 & 26 & & & \\
Preventing Getting Diseases & Yes & 67 & 64 & 1.748 & $0.4-7.6$ & 0.45 \\
& No & 3 & 5 & & & \\
Preventing Spreading of Disease & Yes & 69 & 64 & 5.3 & $0.61-4.7$ & 0.09 \\
& No & 1 & 5 & & & \\
Received Condom Education & Yes & 66 & 68 & 2.9 & $0.89-9.4$ & 0.06 \\
& No & 4 & 12 & & & \\
History of STI & Yes & 13 & 22 & 0.6 & $0.2-1.3$ & 0.19 \\
& No & 57 & 58 & & & \\
\hline
\end{tabular}

Table 5: Association between Significant Others Perceptions and Condom Use

\begin{tabular}{|c|c|c|c|c|c|c|}
\hline Significant Others & & $\begin{array}{l}\text { Con } \\
\text { Con } \\
\text { Yes }\end{array}$ & $\begin{array}{l}\text { stent } \\
\text { om Use } \\
\text { No }\end{array}$ & OR & $95 \% \mathrm{CI}$ & $\mathrm{p}$-value \\
\hline Partners feelings on Condom positive & Yes & 56 & 29 & 7 & 3.3-14 & 0.000068 \\
\hline & No & 14 & 51 & & & \\
\hline Church encourage use of condoms & Yes & $\begin{array}{l}51 \\
14\end{array}$ & $\begin{array}{l}46 \\
25\end{array}$ & 1.9 & $0.92-4.25$ & 0.07 \\
\hline
\end{tabular}

Table 6: Bivariate Analysis-Accessibility to Condom and Condom Use

\begin{tabular}{|c|c|c|c|c|c|c|}
\hline \multirow[t]{2}{*}{ Accessibility of Condoms } & & \multicolumn{2}{|c|}{$\begin{array}{l}\text { Consistent } \\
\text { Condom Use }\end{array}$} & \multirow[t]{2}{*}{ OR } & \multirow[t]{2}{*}{$\mathrm{CI}$} & \multirow[t]{2}{*}{$\begin{array}{l}\mathrm{p}- \\
\text { values }\end{array}$} \\
\hline & & Yes & No & & & \\
\hline \multirow[t]{2}{*}{ Think Condoms affordable } & Yes & 71 & 80 & 1.7 & $0.15-19.9$ & 0.63 \\
\hline & No & 1 & 2 & & & \\
\hline \multirow{2}{*}{$\begin{array}{l}\text { Aware where condoms can be obtained } \\
\text { for free }\end{array}$} & Yes & 71 & 80 & 1.77 & $0.15-19.9$ & 0.63 \\
\hline & No & 1 & 2 & & & \\
\hline \multirow[t]{3}{*}{ Thinks condoms are easily accessible } & Yes & 71 & 79 & 2.6 & $0.7-0.37$ & 0.37 \\
\hline & No & 1 & 2 & & & \\
\hline & No & 69 & 71 & & & \\
\hline
\end{tabular}

Table 7: Perceptions and consistent condom use.

\begin{tabular}{|c|c|c|c|c|c|c|}
\hline \multirow[t]{2}{*}{ Perceptions on Condoms } & & \multicolumn{2}{|c|}{$\begin{array}{l}\text { Consistent } \\
\text { Condom Use }\end{array}$} & \multirow[t]{2}{*}{ OR } & \multirow[t]{2}{*}{ CI } & \multirow[t]{2}{*}{ p-values } \\
\hline & & Yes & No & & & \\
\hline \multirow[t]{2}{*}{ Think Condoms prevent reinfection } & Yes & 63 & 64 & 2.25 & $0.86-5.8$ & 0.08 \\
\hline & No & 7 & 16 & & & \\
\hline \multirow[t]{2}{*}{ Think condoms reduce sexual pleasure } & Yes & 25 & 53 & 0.28 & $0.14-0.5$ & 0.0001 \\
\hline & No & 45 & 27 & & & \\
\hline \multirow{2}{*}{$\begin{array}{l}\text { No need for condoms in long term } \\
\text { relationships }\end{array}$} & Yes & 10 & 29 & 0.29 & $0.13-0.65$ & 0.002 \\
\hline & No & 60 & 51 & & & \\
\hline Find procuring condoms embarrassing & Yes & 5 & 12 & 0.43 & $0.15-1.3$ & 0.12 \\
\hline
\end{tabular}


South American Journal of Public Health

Special Edition May 2016

$\begin{array}{lllllll} & \text { No } & 65 & 68 & & & \\ \text { Thinks condoms for prostitutes } & \text { Yes } & 2 & 9 & 0.23 & 0.04-1.11 & 0.04 \\ & \text { No } & 68 & 71 & & & \\ \text { No need for condoms if HIV positive } & \text { Yes } & 1 & 9 & 0.11 & 0.01-0.92 & 0.016 \\ & \text { No } & 69 & 71 & & & \end{array}$

Table 8. Independent factors for Condom Use

\begin{tabular}{llll}
\hline Factor & $\begin{array}{l}\text { Adjusted Odds } \\
\text { Ratio }\end{array}$ & 95\% CI & p-value \\
\hline Employed & 0.4 & $0.2-0.89$ & 0.023 \\
$\begin{array}{l}\text { Perception that condoms reduce sexual pleasure } \\
\begin{array}{l}\text { Perception that condom should be use by } \\
\text { prostitutes only }\end{array}\end{array}$ & 0.3 & $0.15-0.5$ & 0.0003 \\
$\begin{array}{l}\text { Perception that that there is no need for condoms in } \\
\text { long term relationships }\end{array}$ & 0.2 & $0.11-1.0$ & 0.05 \\
\hline
\end{tabular}

\section{Figures}

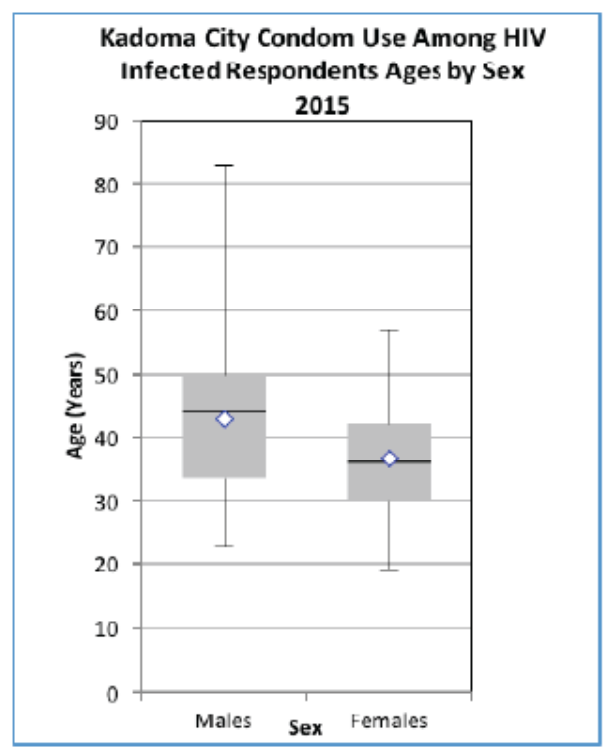

Fig 1: Kadoma City Condom Use among HIV Infected Respondents Ages by Sex 2015

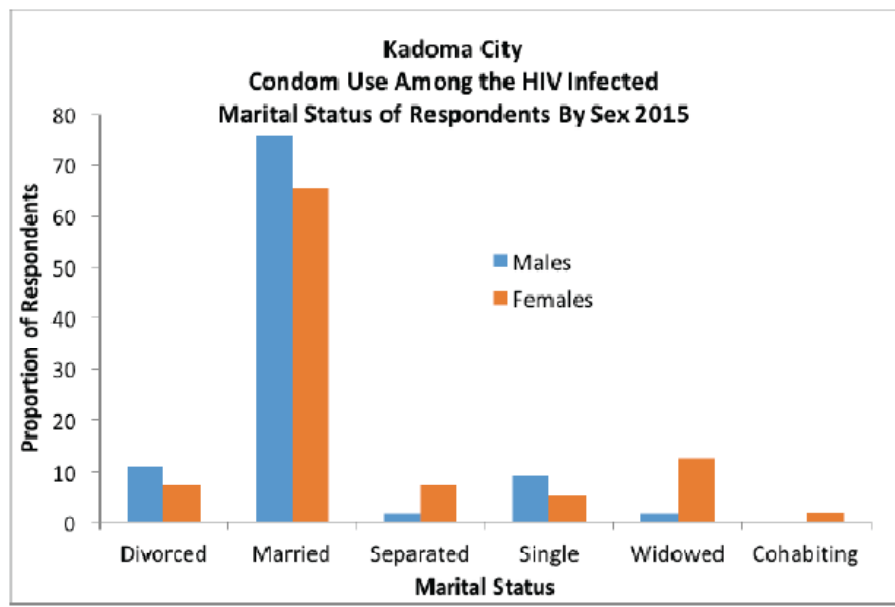

Fig. 2. Kadoma City Condom Use among the HIV Infected 


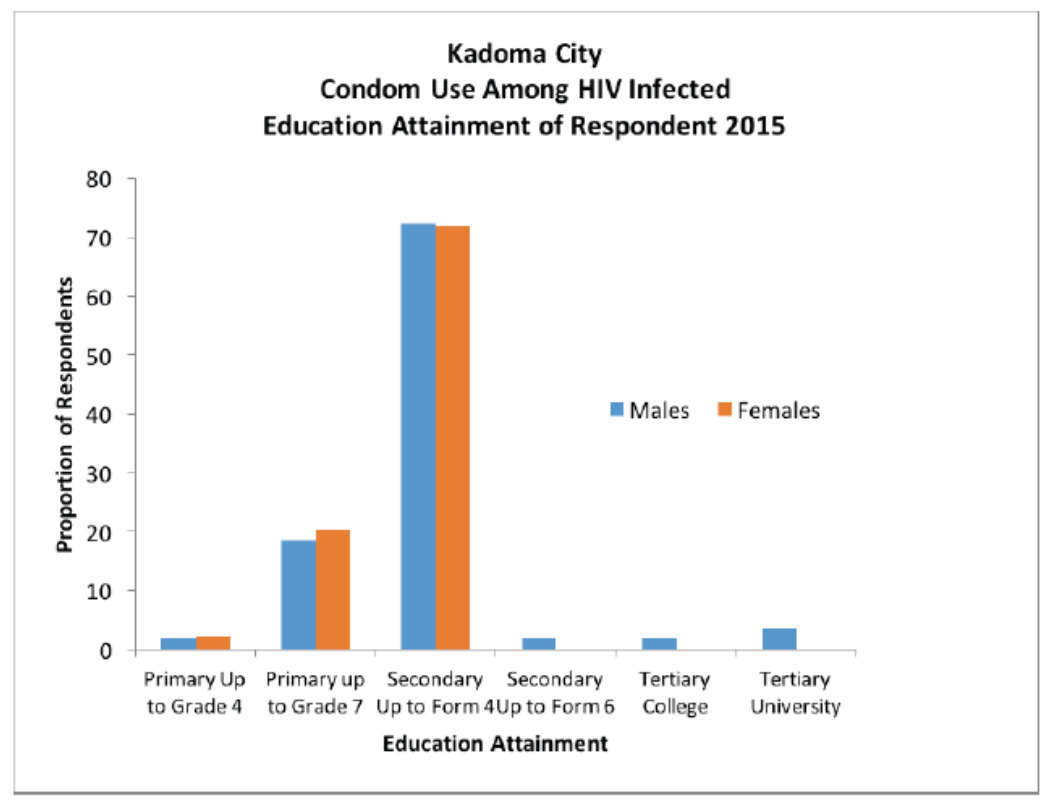

Fig. 3. Kadoma City Condom Use among HIV Infected Education Attainment of Respondent 2015

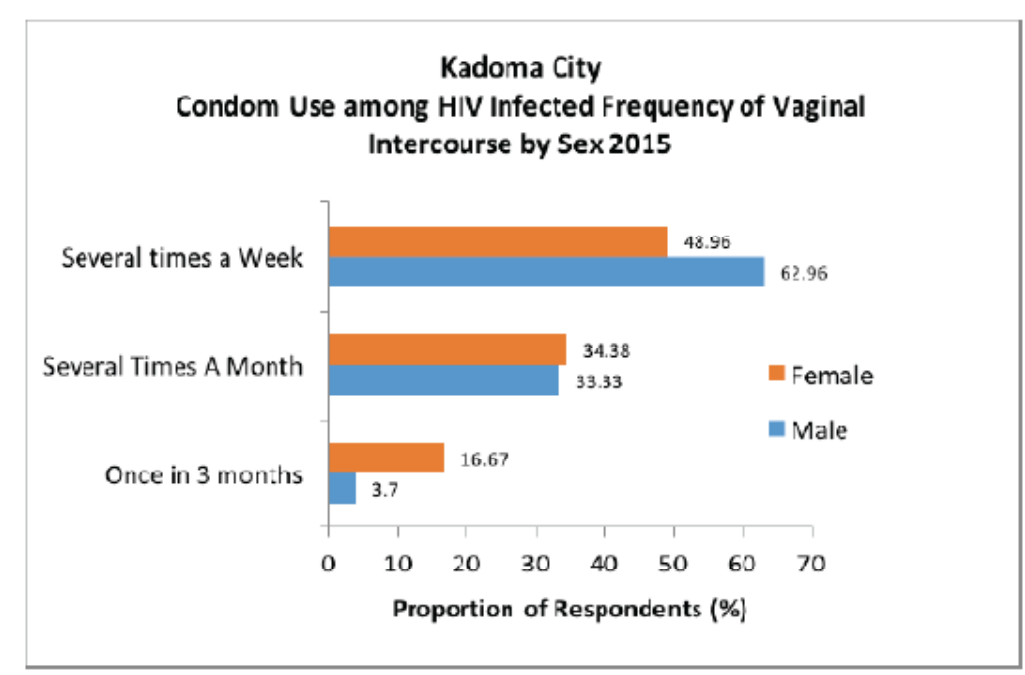

Fig: 4 Condom Use among HIV Infected Frequency of Vaginal Intercourse by Sex 2015 
South American Journal of Public Health

Special Edition May 2016

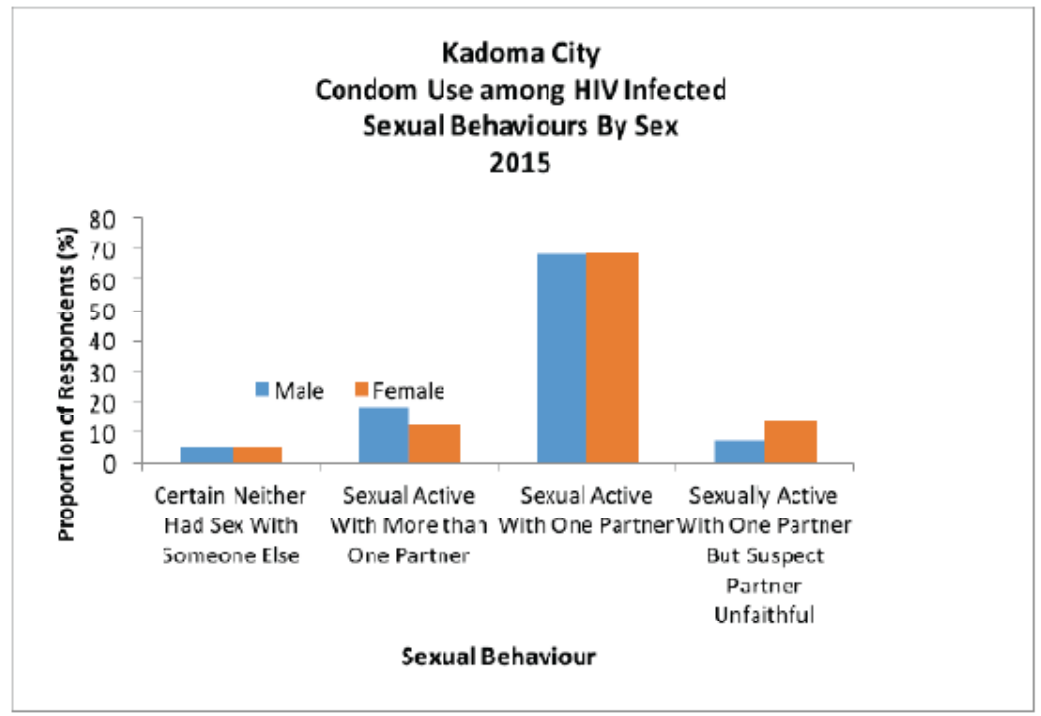

Fig 5: Kadoma City Condom Use among HIV Infected Sexual Behaviors by Sex 2015

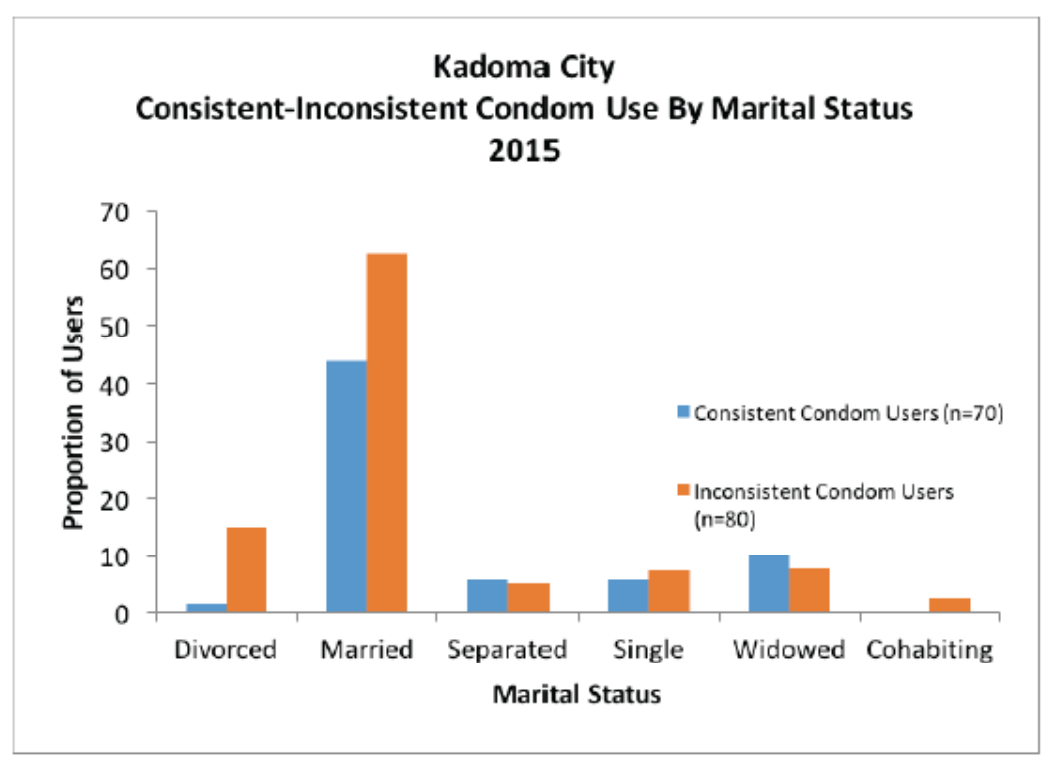

Fig. 6. Kadoma City Consistent-Inconsistent Condom Use by Marital Status 2015 


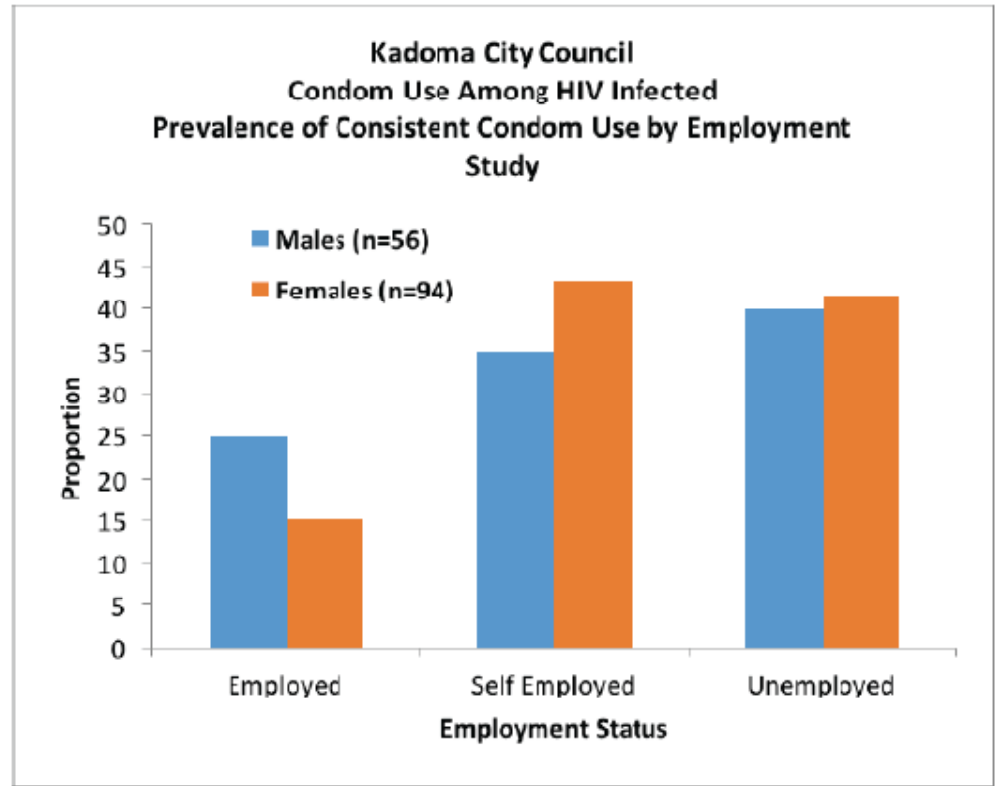

Fig 7: Condom Use among HIV Infected Prevalence of Consistent Condom Use by Employment Study

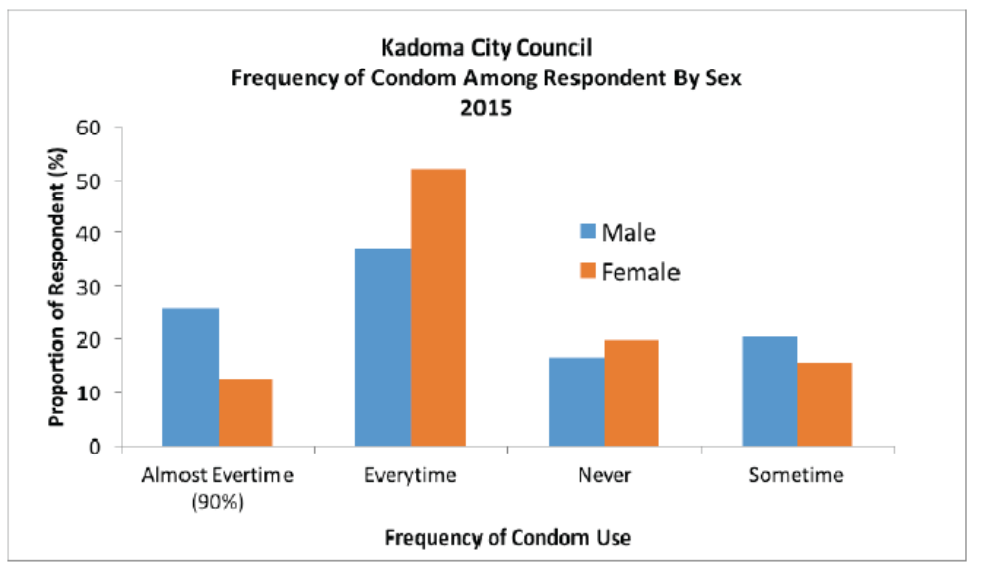

Fig 8. Kadoma City Frequency of Condom Use among Respondents 2015

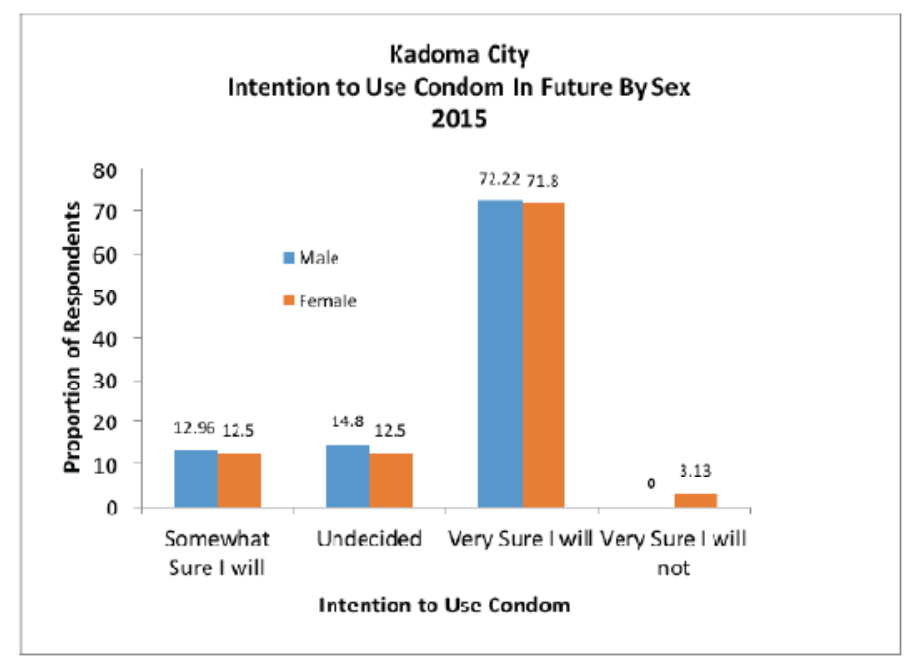

Figure 9: Kadoma City Intention to Use Condom in Future by Sex 2015. 